\title{
Relationship between pregnant women and their partners during COVID-19 and the role of accompanying persons during childbirth
}

\author{
Elizabete Pumpure ${ }^{* 1,2}$, Dace Rezeberga ${ }^{3,4}$, Gunta Lazdane ${ }^{1}$, leva Briedite ${ }^{1}$, Darja Mihailova ${ }^{1}$, leva Pitkevica ${ }^{1}$, Laura \\ Marta Gravina ${ }^{1}$, Solvita Olsena ${ }^{5}$, Inara Kantane ${ }^{1}$, Anda Kīvīte-Urtāne ${ }^{1}$ \\ ${ }^{1}$ Institute of Public Health, Riga Stradins University, Latvia \\ ${ }^{2}$ Riga Maternity Hospital, Latvia \\ ${ }^{3}$ Department of Obstetrics and Gynecology, Riga Stradins University, Latvia \\ ${ }^{4}$ Riga East University Hospital, Latvia \\ ${ }^{5}$ University of Latvia, Latvia
}

Received: March 17, 2021

Accepted: May 27, 2021

Online Published: June 7, 2021

DOI: $10.5430 /$ jha.v10n4p1

URL: https://doi.org/10.5430/jha.v10n4p1

\begin{abstract}
Objective: Although the World Health Organization (WHO) recommends the presence of a support person, several hospitals in Latvia have restricted the presence of supporting persons due to COVID-19. This study was conducted to understand the importance of partnership and the role of the accompanying person in childbirth in the context of COVID-19 in Latvia.

Methods: A mixed method study with sequential explanatory design was conducted from 26 July to 30 October 2020 . The quantitative study consisted of a behavioral cross-sectional online survey with convenience sampling. The survey items, methods, and implementation were performed as part of the I-SHARE study carried out in 33 countries, with standardized survey instruments that were focused on sexual and reproductive health issues. In Latvia it was supported by the National Research Program to lessen the effects of COVID-19. Our study analyses only one part of all data. To answer the research question besides quantitative data the qualitative study that consisted of 7 semi-structured in-depth interviews and 11 focus group discussions was integrated.

Results: 1,173 people of Latvia have participated in the I-SHARE online survey. The answers of 662 women of reproductive age and 70 pregnant women have been analyzed. Pregnant women had less tension with their partners and received higher partner emotional support before the COVID-19 pandemic than other women of reproductive age, and pregnant women were less frustrated during COVID-19 than non-pregnant women of reproductive age $(p<.05)$. More than half $(61.4 \%)$ of the pregnant women felt anxiety and depression due to COVID-19 restrictions. The qualitative part of the study revealed that having a partner during childbirth was an important aspect when choosing a facility to give birth in, as the lack of an accompanying person caused anxiety and additional stress.

Conclusions: COVID-19 has increased anxiety and depression among pregnant women. Birth companions should not be considered third parties, and establishing a delivery unit visitor policy is necessary to balance the benefits and risks in an evidence-based and compassionate manner.
\end{abstract}

Key Words: Childbirth, COVID-19, Partner, Support, Qualitative research

*Correspondence: Elizabete Pumpure; Email: Elizabete.Pumpure@rsu.lv; Address: Miera str. 45, Riga, LV 1013, Latvia. 


\section{INTRODUCTION}

The global COVID-19 pandemic was announced by the World Health Organization (WHO) in March 2020. The specific epidemiological situation and the restrictions imposed by the pandemic have led to substantial changes in all aspects of life, which could have a significant impact on the psychosocial well-being of people. Recent evidence has suggested that pregnant women are not at an increased risk of becoming infected or having a more severe course of the disease or complications than the general population. ${ }^{[1]}$ However, the transition to parenthood, in general, is a potentially vulnerable time for expecting mothers, and $9 \%$ to $21 \%$ of women experience depression or anxiety during pregnancy or the postpartum period. ${ }^{[2]}$ Concerns about becoming infected, the transmission of the virus to the newborn, and taking care of other children and family members have been substantial additional stress factors during the COVID-19 pandemic. Many studies have explored the emotional status of pregnant women during natural disasters, and there is a substantial increase in the levels of anxiety and fear regarding the unpredictability of childbirth. ${ }^{[3]}$

Changes in perinatal care, such as cancelled appointments, remote consultations, and restrictions for partner presence during labor and delivery, can have a negative impact on the course of pregnancy and its outcome. Women's overall well-being is more at risk if they have little support and a poor relationship with their partner. ${ }^{[4]}$

To reduce the spread of infection and the adverse effects of COVID-19 on public health, governments worldwide have introduced social distancing and self-isolation. The Cabinet of Ministers of the Republic of Latvia declared a state of emergency from 13 March to 9 June, 2020 despite the comparatively low incidence of infection in Latvia (see Figure 1). The Order by the Cabinet of Ministers No. 103. "Regarding Declaration of the Emergency Situation" (Article 4.9.), stated that health institutions must restrict visits from a third party. ${ }^{[5]}$ Soon after this order was issued, some perinatal health care institutions prohibited a support person from participating in childbirth.

All perinatal institutions in Latvia providing care for women at high risk extended the denial of the presence of a third party to a support person in childbirth, but several lower-level hospitals did not introduce such prohibitions. The final decision regarding visitor policy was laid on hospital managers and their interpretation of the Order No. 103 by the Cabinet of Ministers.

Partner prohibition might be negatively perceived by women and their families, since emotional support during childbirth plays an important role: it reduces stress levels, increases con- fidence in the process, improves emotional levels, ${ }^{[6]}$ reduces the frequency of complications, and increases the likelihood of a spontaneous vaginal birth. ${ }^{[7]}$ Provision of perinatal care in general, as well as during a pandemic, requires an integrated approach to secure the protection of human rights. The WHO, in addressing human rights as key in the COVID-19 response, stated that integrating both human rights protections and guarantees into our shared responses is not only a moral imperative but is essential to successfully address public health concerns. ${ }^{[8]}$

However, during the pandemic, there is a risk of COVID-19 infection that can threaten not only the health of the mother and child but also the health of medical staff, which may affect the availability and quality of the offered medical services. ${ }^{[9]}$ Governments are trying to balance the rights and health of pregnant women with the threat to public health posed by the epidemiological situation.

This study was conducted to understand the importance of partnerships for pregnant women and the role of the accompanying person in childbirth in the context of COVID-19 in Latvia. This study involved the analysis of the principles applied to perinatal care in Latvia to secure the protection of human rights during pandemics for both patients and healthcare providers.

\section{MATERIAL AND METHODS}

A mixed method study with sequential explanatory design was conducted from July to October, 2020 (see Figure 1). The quantitative study consisted of a behavioral crosssectional online survey with convenience sampling. The survey items, methods, and implementation guidance were selected from a recent UNDP/UNFPA/UNICEF/WHO/World Bank Special Program of Research, Development and Research Training in Human Reproduction (HRP) consensus meeting to develop a standardized survey instrument that focused on sexual and reproductive health (SRH). The survey development was partly based on existing questions and scales and on newly developed questions and was developed for use in 33 countries as part of the I-SHARE study. ${ }^{[10]}$ The goal of the I-SHARE partners was to have at least 500 respondents per country. This network centrally programmed a self-administrated online survey questionnaire using Open Data Kit software (Version 1.16) that could be completed through smartphones, tablets, or computers, such approach was adequate for Latvia because of the high internet user percent. According to the International Telecommunication Union data percentage of individuals, using internet in Latvia in 2020 was $88.9 \%$. ${ }^{[1]}$

The authors organized the translation of the questionnaire 
from English into Latvian and Russian and pilot testing.

Inclusion criteria for the I-SHARE/Latvia survey were persons aged 18 years or older who were currently residing in Latvia and who agreed to the online informed consent10. According to the legislation of Latvia, surveys of people below 18 years require parental consent. Online survey was promoted using traditional (TV \& radio) and social media, and invitation cards which were distributed in antenatal clinics and maternities. Standard fraud protection methods, including CAPTCHA and a measure to prevent more than one response from a single IP address, were included. ${ }^{[12]}$

The socio-demographics were summarized using descriptive statistics (distribution of frequencies, indicators of central tendency and indicators of variability) and non-parametric tests were used in the analysis (chi-square test, Fisher's exact test). In this study women aged less than 50 years were included. To answer the research question, the responses were pooled to conduct sub-analysis on the following groups of individuals: pregnant women vs non-pregnant reproductiveage women, and pregnant women primiparas vs multiparas. The sample size of groups was adequate in comparison. Participants of the survey were representative of the target population. The average age of pregnant women in this study is comparable to the average age of pregnant women in population of Latvia. ${ }^{[13]}$

The data were summarized and analyzed using Microsoft Excel and IBM SPSS 26.0. The results were considered statistically significant if $p<.05$.

Content analysis of the quantitative survey results was used to finalize the qualitative research interview and focus group discussion protocols. The interview and focus group protocols focused mainly on access to information, services and on factors causing anxiety and depression. Core questions were similar in all protocols, but there were questions that differed according to the target group. The qualitative study consisted of 11 semi-structured in-depth interviews with policymakers involved in maternal health, and 7 focus group discussions with 4 to 9 participants representing the target groups: pregnant women, women post-delivery, mothers who delivered between April-May 2020, partners of women post-delivery, and groups of health professionals involved in maternal health care. ${ }^{[14]}$ Participants were approached by research team members mainly for face-to-face interviews in clinics and workplaces, with few exceptions of online interviews. The response rate for participants of focus-group discussions was $80 \%$, main reasons for denial was lack of time due to the newborn care for women in their post-delivery period. The duration of discussions and inter- views were 45-60 minutes and audio recording was done. The methodology of qualitative research was design in line with COREQ (Consolidated criteria for reporting qualitative research) checklist. ${ }^{[15]}$

Quantitative and quantitative research was approved by the Ethical Committee of Riga Stradins University (Nr.6-1/06/25 from 28 May 2020 and $\mathrm{Nr}$ 6-1/08/6 from 23 July, 2020).

Legal research was conducted by combining normative and empirical legal research methods. In the doctrinal legal research, documentary materials such as statutes, regulations, case law, and policy documents were reviewed. Empirical data collected within the project were analyzed from a legal perspective. The combination of the research methods described above helped secure the building of a comprehensive picture concerning the protection of human rights in perinatal care during the COVID-19 pandemic.

\section{Results}

A total of 1,173 people, including 966 women, participated in the online I-SHARE/Latvia survey. A total of 662 women were of reproductive age, 70 were pregnant during the COVID-19 pandemic, and 63 of them gave birth and were included for further analysis for this study to address the research question.

Most of the pregnant women lived in the capital city Riga or another city (72.8\%). All pregnant women had a partner, and $82.9 \%$ had higher education. The average age of the pregnant women was $28.5 \pm 4.5$ years. The pregnant women evaluated their income level before COVID-19 as low (7.1\%), middle $(84.3 \%)$, and high $(8.6 \%)$. A total of $59 / 70(84.3 \%)$ of the pregnant women were employed before the pandemic. When comparing the economic situation and anxieties in pregnant and non-pregnant women, this study did not find significant differences; the situation worsened in both groups (see Table 1).

When analyzing the psychological atmosphere between partners before and during the COVID-19 pandemic, this study found that before COVID-19, there was less tension with partners and substantial emotional support for the group of pregnant women than for the reproductive-age women who were in a partnership but were not pregnant at the time of the survey $(p<.001)$. Pregnant women felt anxious and depressed due to COVID-19 in $61.4 \%$ of cases; however, they were less frustrated than those who were not pregnant $(p=.002)$ (see Table 2). Family relations were influenced by the presence of children. The dynamics of tension with a partner during the COVID-19 restrictions was found to increase significantly in families with children (see Table 3). 
Table 1. Economic situation of pregnant women in comparison with non-pregnant women of reproductive age during the COVID-19 pandemic

\begin{tabular}{llll}
\hline & $\begin{array}{l}\text { Pregnant woman } \\
\mathbf{n}(\boldsymbol{\%})\end{array}$ & $\begin{array}{l}\text { Non-pregnant woman } \\
\mathbf{n}(\boldsymbol{\%})\end{array}$ & $\boldsymbol{p}$-value \\
\hline Lost job/work/business & $8 / 51(15.7)$ & $43 / 451(9.5)$ & .168 \\
Economic situation of the family deteriorated & $24 / 70(34.3)$ & $176(26.7)$ & .174 \\
Worrying about the financial situation in the family & $37 / 57(64.4)$ & $382 / 529(72.2)$ & .246 \\
\hline
\end{tabular}

Table 2. Partner support and emotional status of pregnant women in comparison with non-pregnant women of reproductive age

\begin{tabular}{|c|c|c|c|}
\hline & $\begin{array}{l}\text { Pregnant woman } \\
\text { n }(\%)\end{array}$ & $\begin{array}{l}\text { Non-pregnant woman } \\
\text { n }(\%)\end{array}$ & $p$-value \\
\hline Never had tension with partner before COVID-19 & $27 / 70(38.6)$ & $108 / 662(16.3)$ & $<.001$ \\
\hline Less tension with partner during COVID-19 than before & $21 / 70(30.0)$ & $128 / 521(24.6)$ & .443 \\
\hline Substantial emotional support from partner before COVID-19 & $68 / 70(97.1)$ & $478 / 662(72.2)$ & $<.001$ \\
\hline More emotional support during COVID-19 than before & $19 / 70(27.1)$ & $114 / 520(21.9)$ & .156 \\
\hline Frustrated due to COVID-19 restrictions & $13 / 70(18.5)$ & $248 / 659(37.6)$ & .002 \\
\hline Confused about what is/is not allowed during the COVID-19 restrictions & $22 / 70(31.4)$ & $158 / 659(24.0)$ & .218 \\
\hline
\end{tabular}

Table 3. Partner support and emotional status of first-time pregnant women in comparison with multiparas

\begin{tabular}{llll}
\hline & $\begin{array}{l}\text { Primiparous } \\
\mathbf{n}(\boldsymbol{\%})\end{array}$ & $\begin{array}{l}\text { Multiparous } \\
\mathbf{n}(\boldsymbol{\%})\end{array}$ & $\boldsymbol{p}$-value \\
\hline Never had tension with partner before COVID-19 pandemic & $15 / 37(40.5)$ & $12 / 33(36.4)$ & .720 \\
More tension during COVID-19 & $7 / 37(18.9)$ & $11 / 33(33.3)$ & .026 \\
Substantial emotional support before COVID-19 & $29 / 37(78.4)$ & $20 / 33(60.6)$ & .139 \\
More emotional support during COVID-19 & $8 / 37(21.6)$ & $11 / 33(33.3)$ & .334 \\
Frustrated due to COVID-19 restrictions & $14 / 37(37.8)$ & $9 / 33(27.3)$ & .466 \\
Anxiety and depression due to COVID-19 restrictions & $23 / 37(61.2)$ & $20 / 33(60.6)$ & .210 \\
Confused about what is/is not allowed during COVID-19 restrictions & $12 / 37(32.4)$ & $10 / 33(30.3)$ & .130 \\
\hline
\end{tabular}

The findings of the qualitative research (see Table 4) provide additional information for a better understanding of the impact of COVID-19 restrictions on maternal health in Latvia. Most of the women's anxiety was about the unclear and constantly changing guidance regarding restrictions in maternities caused worries, additional stress, and risks regarding the quality of care.

Human rights considerations regarding restrictive measures, in an attempt to reduce transmission and minimize the impact of COVID-19, should be implemented in line with the principles articulated in the UN Committee on Economic, Social and Cultural Rights General Comment (No. 14) ${ }^{[16]}$ and the International Covenant on Civil and Political Rights (ICCPR). ${ }^{[17]}$ They should also be further elaborated in the
Siracusa Principles, ${ }^{[18]}$ whereby any such restrictive measures should be in accordance with the law and pursue a legitimate aim that is proportionate and not arbitrary or discriminatory. ${ }^{[8]}$ The Latvian Constitution (1922) states the same principles with respect to the restriction of individual human rights in a state of emergency. If necessary, the restrictions must be issued in accordance with the procedures laid down in the legislation, meaning that Parliament or the Cabinet of Ministers should issue regulations restricting human rights in health care. Healthcare institutions are obliged to respect and fulfil patients' rights and abstain from unlawful restrictions.

The legal research revealed that hospital authorities have been misinterpreting and incorrectly applying Article 4.9. of 
the Cabinet's Order in a state of emergency. First, the legal norm states that a healthcare institution shall restrict the visits of third persons. The norm does not state the requirement or permission to prohibit visits. Second, the participation of a support person in childbirth should not be interpreted as a visit to a third person. It is an integral component of high-quality childbirth assistance and secures the respect for the patient's rights to self-determination and a private life. Third, a support person in childbirth who is the father of a newborn is legally not considered to be a third party or a visitor. Immediately after a child is born, the father becomes a legal representative of the child and has individual rights with respect to the child.

Table 4. Findings from the qualitative research12: Various perspectives and opinions regarding the presence of a companion during childbirth

\begin{tabular}{|c|c|}
\hline & Perspectives and opinions \\
\hline Anxiety & $\begin{array}{l}\text { Situations in which women were not allowed to have a partner present was a significant stress for them. } \\
\text { First-time delivery patients were more frequently looking for places where participation of the support } \\
\text { person was not restricted. Multiparas felt much safer. (Midwife, focus group discussion) } \\
\text { The support person was missed the most during the postpartum period, especially if the woman had a } \\
\text { difficult birth or complications. (Midwife, focus group discussion) } \\
\text { Safety considerations are crucial when choosing a birthplace at the sacrifice of the emotional comfort of } \\
\text { being together. (Partner, focus group discussion) }\end{array}$ \\
\hline $\begin{array}{l}\text { Additional stress and } \\
\text { financial burden }\end{array}$ & $\begin{array}{l}\text { My husband and I had a detailed plan for how to prepare for the delivery process and the period after it, } \\
\text { but our dreams did not come true. ... We managed only to attend two pregnancy classes, but my husband } \\
\text { was a great support. Because it was twins, I had not much choice. ... I cried for a day but then took the } \\
\text { decision to choose the hospital that was best for the babies and myself. I ended up having a Cesarean } \\
\text { section and I really missed my husband's help. ... The staff were very busy and could not help me that } \\
\text { much. It was very stressful. (Woman, focus group discussion) } \\
\text { The rules that the husband would not be able to attend the birth came suddenly, but there were hospitals } \\
\text { where the husband could participate, and I was ready to sign a contract and pay for that, just to ensure my } \\
\text { husband's presence. (Woman, focus group discussion) } \\
\text { A support person during delivery is important, especially for first-time delivery patients without } \\
\text { experience. There was restricted access for delivery classes, and previous registration was required; } \\
\text { courses were cancelled without prior notice. I learned from my mother, read books, but it was in theory, } \\
\text { and I lacked the practical part. (Woman, focus group discussion) }\end{array}$ \\
\hline $\begin{array}{l}\text { Risks regarding } \\
\text { quality of care }\end{array}$ & $\begin{array}{l}\text { Prohibiting the presence of partners is somewhat dangerous; the patient can hide her health problems just } \\
\text { to be permitted to give birth in a lower-level hospital. (Hospital administrator, personal in-depth interview) } \\
\text { Due to the absence of the partners who could help women after Cesarean sections and complicated births, } \\
\text { the workload for midwives and nurses was higher, and they were not always available to help when called. } \\
\text { (Healthcare provider, focus group discussion) } \\
\text { There are no common, precise guidelines that are specifically for the participation of accompanying } \\
\text { persons in childbirth. The decision has to be made by hospital managers in their particular circumstances. } \\
\text { That is not an easy task. (Hospital administrator, personal in-depth interview) }\end{array}$ \\
\hline
\end{tabular}

\section{Discussion}

Women in Latvian society play a powerful role: their average education level is higher than men, their employment status is higher than average in the European Union (EU), ${ }^{[19]}$ and the total fertility rate in 2018 was 1.6 , while the average in the EU was only $1.55 .{ }^{[20]}$ The current study's population of pregnant women was similar to these characteristics, since the women were highly educated; had their own incomes;

Published by Sciedu Press and $52 \%$ had children, which, accordingly, fulfilled a number of roles related to the well-being of the family.

COVID-19-related restrictions changed the social and economic situation in many families and households in Latvia, creating uncertainty about the future. Recent research has identified the top stressors faced by families as employment and children's well-being: ${ }^{[21]}$ both showed an impact on the emotional well-being of a pregnant woman in the current 
study. Many participants pointed out that their economic situations worsened during the pandemic (see Table 1), and having children negatively influenced their relationship with their partners. One-fifth of the pregnant women during the COVID-19 pandemic felt more frustrated than before, but this finding was more evident in the non-pregnant women (see Table 2). This can be partly explained by the existing partner support for all pregnant participants; most of whom confirmed that they received emotional support from their partners before the COVID-19 pandemic, while two-fifths never had tension with their partner before the pandemic. During the pandemic, more than one-quarter of pregnant women noticed a higher degree of support (see Table 2). Therefore, it is not surprising that during the group discussions, the women admitted that their partner's presence was crucial during childbirth, and this finding was identified in other studies. ${ }^{[22,23]}$ A high frequency of maternal mental health problems, such as clinically relevant anxiety and depression, during the pandemic has been reported in many countries. ${ }^{[24]}$ The results from the current study indicate that the percentage of anxiety and depression during the pandemic is almost three to five times more frequent than before. $^{[2]}$

Global social networks, other studies, ${ }^{[25]}$ and the current study's results indicate that one of the most controversial issues in maternity care provision during the COVID-19 pandemic has been whether to allow the presence of a support person during childbirth. ${ }^{[26]}$ For most women, a positive experience means giving birth to a healthy baby in a clinically and psychologically safe environment with practical and emotional support from a birth companion and competent, reassuring, and kind clinical staff. ${ }^{[27]}$ The WHO has stated that all women have the right to a safe and positive childbirth experience during the pandemic, and that includes having a companion of their choice with them. ${ }^{[28]}$

The pregnant women, mothers, and fathers involved in the current study stated that the restrictions came suddenly and unexpectedly. By focusing on epidemiological safety, the emotional well-being of a pregnant woman was left out. In the current study, Latvian midwives confirmed that the restriction of a partner present during childbirth was a significant stress for women, especially for those who were giving birth for the first time, which has also been recognized in other studies. $^{[7]}$

The women and their partners who participated in the group discussions emphasized the importance of the presence of a partner as one of the main criteria of choosing a place to give birth in. In a study carried out during the COVID-19 pandemic, expectant mothers who believed that their partner could not be present during childbirth or would be denied 6 visitation were more likely to have higher levels of anxiety or a severe fear of childbirth. ${ }^{[29]}$

In order to understand whether the restrictions on the partner's presence affected the number of births in delivery wards in Latvia, we compared the data of the Latvian Newborn registry during the state of emergency period in 2020 with a similar period in 2019. Data indicated there was a decrease (up to $33 \%$ ) in the number of births in hospitals when a partner's presence was prohibited, and an increase (up to 50\%) in maternities when partners could be present but the average number of births in was almost the same, and the planned home delivery rate remained the same in 2019 and 2020. ${ }^{30]}$ Studies conducted in the United States have indicated that during the COVID-19 pandemic, the demand for home births has increased, which is also associated with women's fear of COVID-19 in a medical institute. Despite the possible risks, women have purposefully expressed their desire for planned birth at home to have emotional support from their partner during childbirth. ${ }^{[23,31]}$

Before the COVID-19 pandemic, no one expected that basic care such as having a companion of choice during childbirth could be forbidden. Recommendations to outweigh the risks and benefits were released, and most stated that the continuity of the maternity services was essential and that the decision on whether to allowing birthing partners should rely on hospital managers, ${ }^{[9]}$ as that was the case in Latvia. ${ }^{[5,14]}$ The COVID-19 pandemic poses a risk not only with restrictions on the presence of a partner, but also with the availability of competent staff if the spread of the infection becomes uncontrollable. There is a threat of collapse in healthcare systems, risk of transmission of the virus to healthy patients and staff, ${ }^{[32]}$ and possible psychological stress among healthcare providers. ${ }^{[33]}$ Hospital management is faced with the difficult decision of how to balance the interests of the individual with the need to limit the risk of care providers from becoming infected. ${ }^{[26]}$ The latter policies try to balance the benefits to the individual patient with the task of reducing infectious exposure to other patients and health care teams, thus prioritizing the health of the community. ${ }^{[9]}$ Simultaneously, in this study's semi-structured interview, hospital managers expressed doubts about safety considerations, mentioning that patients could hide their health problems just to be permitted to give birth in a lower-level hospital.

Latvia stood out as one of the countries with the lowest COVID-19 cumulative incidence rate during March and April 2020 (see Figure 1), yet experiences from other countries made hospital managers cautious, and one of the most frequent non-evidence-based decisions was to prohibit the presence of birthing partners during this time to limit the spread of the virus.

ISSN 1927-6990 E-ISSN 1927-7008 


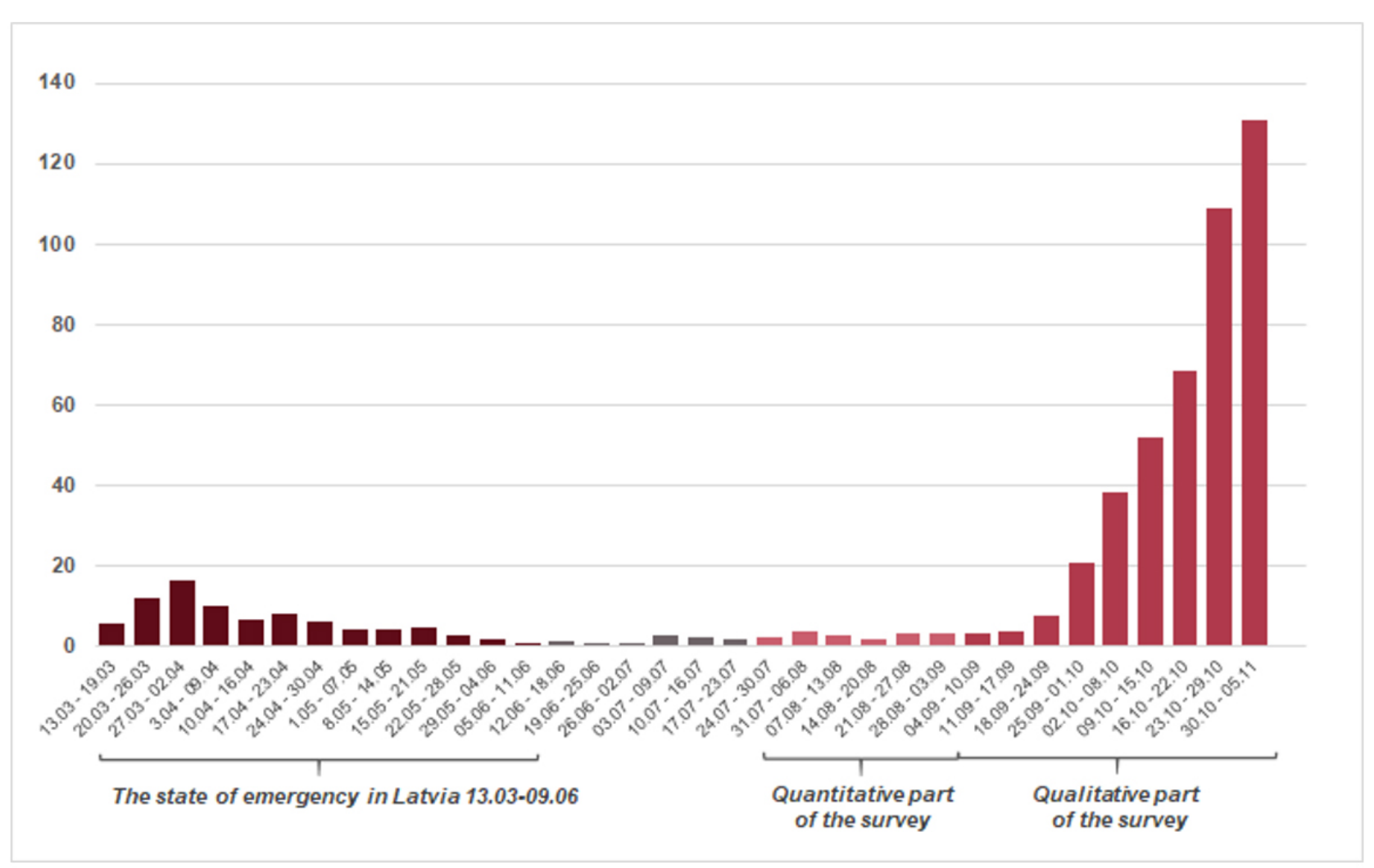

Figure 1. Daily new confirmed COVID-19 cases per million people in Latvia (7-day average), period of state of emergency in Latvia, and the study timeline

Latvian healthcare policymakers delegated the decision of a partner's presence to maternity hospital managers. Lack of up-to-date and interactive information from healthcare institutions increased confusion and stress among expectant mothers and their partners ${ }^{[14]}$ (see Table 4).

Faced with the COVID-19 pandemic's time constraints, pregnant women as well as health care staff in the group discussions admitted that modern means of communication provided the possibility of reducing the stress of separation. The broader use of telemedicine and telecommunication was recommended as part of regular obstetric care communications in a variety of constraints, even before the pandemic. ${ }^{[26]}$

The main weakness of this study is the comparatively low number of pregnant women in the quantitative part of the study, yet the strength of the study is in the qualitative part, which provides additional value for preparing recommendations for policymakers regarding a support person during delivery. The qualitative part of the study provides information about the additional aspects that should be taken into consideration when planning maternal health services in pandemic situations.

In Latvia, the incidence rate of COVID-19 during the study was relatively low, which should be taken into account when comparing the results of the survey, interviews, and group discussions with similar studies in other countries. Responders of online questionnaires may not represent pregnant women of lower social classes due to their limited access to Internet resources.

\section{Conclusions}

The lack of experience in providing maternal health services during the spread of COVID-19 with no pre-existing guidelines and clinical data resulted in non-evidence-based regulations that increased the stress, anxiety and depression of pregnant women and their family members and increased the workload of maternity staff. The presence of a partner during childbirth is essential for most women and maternity care providers, and choice of birthplace can be influenced by visitor policies in delivery wards, making safety issues regarding maternity care less significant. Birth companions should not be considered a third party, and their presence during childbirth is a woman's human right. The legal regulations and visitor policies should predict situations that partner of choice is not a biological father of a newborn. Establishing a labor and delivery unit visitor policy is necessary to balance the benefits and risks to the patient, community, and health care team in an evidence-based and compassionate manner. 
In order to ensure equal rights for patients the policies in hospitals should be uniform and well communicated.

\section{ACKNOWLEDGements}

This study was done in the context of the I-SHARE study (International Sexual Health And REproductive Health), which examines the impact of the COVID-19 crisis on sexual and reproductive health in diverse low-income, middleincome, and high-income countries. The full list of consortium members and their roles can be found here (https: //ishare.web.unc.edu). We would like to thank the ISHARE Consortium for their co-operation and those who participated in the online survey, group discussions, and interviews.

\section{FUNDING}

The study was financed and conducted as a part of the National Research Program project "Impact of COVID-19 on health care system and public health in Latvia; ways in preparing health sector for future epidemics" (Project Nr. VPP-COVID-2020/1-0011).

\section{CONFlicts OF InTEREST Disclosure}

The authors declare they have no conflicts of interest.

\section{REFERENCES}

[1] Royal College of Obstetricians and Gynaecologists (RCOG) and The Royal College of Midwives. Coronavirus (COVID-19) infection in pregnancy. Accessed November 27, 2020. Available from: https://www.rcog.org.uk/globalassets/documents/gui delines/2020-10-14-coronavirus-covid-19-infection -in-pregnancy-v12.pdf

[2] McLeish J, Redshaw M. Mothers' accounts of the impact on emotional wellbeing of organised peer support in pregnancy and early parenthood: a qualitative study. BMC Pregnancy Childbirth. 2017; 17(28). PMid: 28086827. https://doi.org/10.1186/s12884 $-017-1220-0$

[3] Qu Z, Tian D, Zhang Q, et al. The impact of the catastrophic earthquake in China's Sichuan province on the mental health of pregnant women. J Affect Disord. 2012; 136(1-2): 117-123. PMid: 21937121. https://doi.org/10.1016/j.jad.2011.08.021

[4] Pilkington P, Milne L, Cairns K, et al. Enhancing reciprocal partner support to prevent perinatal depression and anxiety: a Delphi consensus study. BMC Psychiatry. 2016; 16(23). PMid: 26842065. https://doi.org/10.1186/s12888-016-0721-0

[5] Ministry of Health of the Republic of Latvia. About restriction of health care services during COVID-19 emergency situation. Law Nr. 59. Accessed December 27, 2020. Available from: https: $/ / \mathrm{m}$. likumi.lv/doc.php?id=313481\&fbclid=IwAR3q_3nXF8 7F3C53-98pgbwDG51XsEu1uj9Ln139HtDeRrPmC-dSMwZ1Dbo

[6] Wilson CL, Simpson JA. Childbirth pain, attachment orientations, and romantic partner support during labor and delivery. Pers. Relationship. 2016; 23(4): 622-644. PMid: 28529444. https : //doi .or g/10.1111/pere. 12157

[7] Bohren MA, Hofmeyr GJ, Sakala C, et al. Continuous support for women during childbirth. Cochrane Database Syst. Rev. 2017; 7(7). PMid: 28681500. https://doi.org/10.1002/14651858.CD0 03766.pub6

[8] World Health Organization. Addressing human rights as key to the COVID-19 response. Accessed December 26, 2020. Available from: https://www.who.int/publications/i/item/addres sing-human-rights-as-key-to-the-covid-19-response

[9] Arora KS, Mauch JT, Gibson KS. Labor and delivery visitor policies during the COVID-19 pandemic: balancing risks and Benefits. JAMA. 2020; 323(24): 2468-2469. PMid: 32442264. https : //doi.org/10.1001/jama.2020.7563

[10] Michielsen K, Larrson EC, Kågesten A, et al. International sexual health and reproductive health (I-SHARE) survey during COVID-19: study protocol for online national surveys and global comparative analyses. Sex Transm Infect. 2021; 97: 88-92. PMid: 33082232. https://doi.org/10.1136/sextrans-2020-054664

[11] International Telecommunication Unit. Statistics. Accessed May 20, 2021. Available from: https://www.itu.int/en/ITU-D/Stati stics/Pages/stat/default.aspx

[12] Lazdane G, Rezeberga D, Briedite I, et al. Sexual and reproductive health survey in the time of COVID-19 - Latvia [dataset]. 2021 Feb 18. RSU DataVerse Repository. Available from: https : //doi.org/10.25143/FK2/J5KXXD

[13] Official statistics portal - official statistics of Latvia. Average age of mother at childbirth. Accessed May 20, 2021. Available from: https://stat.gov.lv/en/statistics-themes/popu lation/fertility/241-average-age-mother-childbirth

[14] Lazdane G, Rezeberga D, Briedite I, et al. Sexual and reproductive health in the time of COVID-19 in Latvia, qualitative research interviews and focus group discussions (in Latvian) [dataset]. RSU DataVerse Repository. 2021 Feb 25. https ://doi .org/10. 25143 /FK2/LXKU5A

[15] Tong A, Sainsbury P, Craig J. Consolidated criteria for reporting qualitative research (COREQ): a 32-item checklist for interviews and focus groups. International Journal for Quality in Health Care. 2007; 19(6). PMid: 17872937. https://doi.org/10.1093/intqhc/mzm042

[16] The United Nations Committee on Economic, Social and Cultural Rights (CESCR). General Comment No. 14: The Right to the Highest Attainable Standard of Health (Art. 12 of the Covenant). Accessed February 25, 2021. Available from: https://www.refworld.org /docid/4538838do.html

[17] The United Nations General Assembly. International Covenant on Civil and Political Rights. Treaty Series. Accessed February 25, 2021. Available from: https://www.ohchr.org/en/professionali nterest/pages/ccpr.aspx

[18] The United Nations Commission on Human Rights. The Siracusa Principles on the Limitation and Derogation Provisions in the International Covenant on Civil and Political Rights. Accessed February 25, 2021. Available from: https://www.refworld.org/docid/467 2bc122.html

[19] Central Statistical bureau of Latvia. Women and men in Latvia. Accessed February 28, 2021. Available from: https://www.csb.gov.lv/en/statistics/statistic s-by-theme/population/characteristics/search-in-t heme/205-women-and-men-latvia-2016 
[20] Eurostat. Fertility statistics. Accessed February 28, 2021. Available from: https://ec.europa.eu/eurostat/statistics-expla ined/index.php/Fertility_statistics\#live_births_pe r_woman_in_the_EU_in_2018

[21] Evans S, Mirocka-Walus A, Klas A, et al. From "it has stopped our lives" to "spending more time together has strengthened bonds": the varied experiences of Australian families during COVID-19. Front Psychol. 2020; 11. PMid: 33192922. https://doi.org/10.338 9/fpsyg. 2020.588667

[22] Cheng ER, Rifas-Shiman SL, Rifas-Shiman SL, et al. The influence of antenatal partner support on pregnancy outcomes. J Women's Health. 2016; 25(7): 672-679. PMid: 26828630. https://doi.or g/10.1089/jwh. 2015.5462

[23] Davis-Floyd R, Gutschow K, Schwartz DA. Pregnancy, birthandthe COVID-19 Pandemic in the United States. Med Anthropol. 2020; 39(5): 413-427. PMid: 32406755. https://doi.org/10.1080/ 01459740.2020 .1761804

[24] Kotlar B, Gerson E, Petrillo S, et al. The impact of the COVID-19 pandemic on maternal and perinatal health: a scoping review. Reprod Health. 2021; 18(10). PMid: 33461593. https ://doi.org/10.1 186/s12978-021-01070-6

[25] Sherwood H. Partners still banned from UK maternity wards despite rule change. Accessed December 27, 2020. Available from: https ://www . theguardian.com/money/2020/oct/24/part ners-still-banned-from-uk-maternity-wards-despite -rule-change

[26] Berghella V, Hughes B. Coronavirus disease 2019 (COVID-19): labor, delivery, and postpartum issues and care. Accessed November 13, 2020. Available from: https://www-uptodate-com.db.rs u.1v/contents/coronavirus-disease-2019-covid-19-1 abor-delivery-and-postpartum-issues-and-care?sear ch=pregnancy $\% 20$ covid\&source=search_result\&selectedT itle=3 150\&usage_type=default\&display_rank=3

[27] Downe S, Finlayson K, Oladapo OT, et al. What matters to women during childbirth: a systematic qualitative review. PLoS One. 2018; 13(4): e0194906. PMid: 29664907. https ://doi.org/10.1371/ journal.pone.0194906

[28] World Health Organization. Every woman's right to a companion of choice during childbirth. Available from: https: //www . who. int/news/item/09-09-2020-every-woman-s-r ight-to-a-companion-of-choice-during-childbirth

[29] Molgora S, Accordini M. Motherhood in the time of Coronavirus: the impact of the pandemic emergency on expectant and postpartum women's psychological well-being. Front Psychol. 2020; 26(11): 567155. PMid: 33192847. https://doi.org/10.3389/fpsyg. 2020.567155

[30] Latvian Centre for Disease Prevention and Control. Medical statistics database. Accessed December 27, 2020. Available from: https : //statistika.spkc.gov.1v/pxweb/lv/Health/

[31] Premkumar A, Cassimatis I, Berhie SH, et al. Home birth in the era of COVID-19: counseling and preparation for pregnant persons living with HIV. Am J Perinat. 2020; 37(10): 1038-1043. PMid: 32498092. https://doi.org/10.1055/s-0040-1712513

[32] Sharma JB, Sharma E. Obstetrics and COVID-19. J Pak Med Assoc. 2020; 70(Suppl 3: 5): S104-S107. PMid: 32515390. https : //doi.org/10.5455/JPMA. 24

[33] Vafaei H, Roozmeh S, Hessami K, et al. Obstetrics healthcare providers' mental health and quality of life during COVID-19 pandemic: multi-center study from eight cities in Iran. Psychol Res Behav Manag. 2020; 17(13): 563-571. PMid: 32765131. https : //doi.org/10.2147/PRBM.S256780 